\title{
Changes in Foliar Host Reaction to Ascochyta Rabiei With Plant Maturity
}

\author{
Vicki L. Elliott ${ }^{1}$, Paul W. J. Taylor ${ }^{2} \&$ Rebecca Ford $^{2}$ \\ ${ }^{1}$ Melbourne School of Land and Environment, The University of Melbourne, Grains Innovation Park, Horsham, \\ Victoria, Australia \\ ${ }^{2}$ Melbourne School of Land and Environment, The University of Melbourne, Parkville, Victoria, Australia \\ Correspondence: Vicki Elliott, Melbourne School of Land and Environment, The University of Meblourne, Grains \\ Innovation Park, Horsham, Melbourne, Australia. Tel: 61-3-5381-2294. E-mail: velliott@unimelb.edu.au
}

Received: March 27, 2013 Accepted: April 27, 2013 Online Published: June 15, 2013

doi:10.5539/jas.v5n7p29 URL: http://dx.doi.org/10.5539/jas.v5n7p29

\begin{abstract}
Ascochyta rabiei is the most significant foliar disease of chickpea (Cicer arietinum) worldwide, and can cause both yield loss and reduced seed quality. Significant mean disease score differences were observed from the reactions among a collection of Ascochyta rabiei isolates and chickpea hosts at both seedling and maturity growth stages $(\mathrm{P}<0.000)$. Although isolates ranked similarly within their range of pathogenicity at either growth stage, the ranking of host disease reaction was different. This suggests that genotype-specific expression of resistance genes to A. rabiei may be related to growth stage. Hence, durable selection methods for resistance will require screening of isolates representative of the pathogenicity within the population on target genotypes at growth stages representative of the type of resistance being sought, for example seedling resistance or pod resistance.
\end{abstract}

Keywords: Ascochyta rabiei, Cicer arietinum, host plant resistance, plant maturity

\section{Introduction}

The most significant foliar disease of chickpea (Cicer arietinum) worldwide is Ascochyta blight (causal agent Ascochyta rabiei (Pass.) Labrousse, teleomorph Didymella rabiei (Kovachevski) von Arx. All aerial parts of the host are affected (Nene \& Reddy, 1987; Pande et al., 2005) as are both yield and seed quality, and complete yield losses have been reported (Kaiser \& Muehlbaur, 1988; Navas-Cortes et al., 1998). The inoculum originates from infected seed and previous season stubble, and secondary infections are spread throughout the crop by rain splash (Pande et al., 2005). Therefore, plants may become infected at a number of stages in their life cycle, dependent on inoculum level and epidemiological conditions. Although marketed as 'resistant', recently implemented Australian cultivars are susceptible to the disease at maturity (podding). Although cultivars such as Genesis 090 demonstrated strong resistance at the seedling stage, infection later in the season resulted in pod abortion, or reduced seed quality (Pulse Australia 2011), hence fungicide application at maturity is prescribed as part of the best practice for disease management along with stubble removal, minimum four year rotations and seed dressing (Pulse Australia 2011).

Resistance to A. rabiei is quantitatively governed with multiple genes contributing to the overall resistance trait (Santra, Tekeoglu, Ratnaparkhe, Kaiser, \& Muehlbaur, 2000; Lichtenzveig, Shtienberg, Zhang, Bonfil, \& Abbo, 2002; Flandez-Galvez, Ford, Ades, Pang, \& Taylor, 2003; Flandez-Galvez, Ford, Pang, \& Taylor, 2003; Udupa \& Baum, 2003). It is likely that expression of individual resistance genes is triggered by external (environmental/pathogen) and internal (plant age/pathogen) stimuli. Expression of each of these genes can differ at different times in the plants life (Trapero-Casas \& Kaiser, 1992; Chongo \& Gossen, 2001; Sharma, Pande, \& Rathore, 2010), and hence cultivars which show good seedling resistance may not have the same highly effective resistance at maturity. The resistance level to A. rabiei has previously been correlated with chickpea plant age (Nene \& Reddy, 1987; Chongo \& Gossen, 2001; Basandrai et al., 2007; Sharma et al., 2010). Chongo \& Gossen, (2001) and Basandrai et al. (2007) found reduced resistance at flowering and podding compared to earlier growth stages except in susceptible cultivars where plant growth stage had no effect on disease severity. Sharma et al. (2010) also found more disease on resistant cultivars at flowering and podding, which did not correlate well with the resistance observed during vegetative growth. 
Control methods in Australia recommend fungicide application at podding even in the more resistant cultivars. If breeding material can be found that contains effective resistance at the flowering and podding stages chickpea growers may be able to reduce their reliance on fungicides, and reduce the likelihood of fungicide tolerance becoming a problem in the future. To ensure a stable Australian chickpea industry, genotypes must be identified that contain resistance effective throughout the cropping season and on exposure to the diversity of isolate pathogenicities that exist in the population.

This study aimed to 1) assess and compare the levels of resistance that Australian bred genotypes have at seedling verses maturity to isolates representative of the Australian A. rabiei pathogenic population; and 2) identify isolates that are pathogenic at both host growth stages assessed and that should be used in future breeding programs.

\section{Methodology}

\subsection{Isolate and Host Material}

Six isolates representative of the variation in pathogenicity within the $A$. rabiei populations in Victoria and South Australia in the 2009 season were selected based on their pathogenicity over 12 chickpea genotypes (Table 1; Elliott et al., 2011). The isolates were collected using the two methods outlined in Elliott, Taylor, and Ford (2011).

Table 1. Ascochyta rabiei isolates used, their location of collection and cultivar from which they were recovered

\begin{tabular}{lll}
\hline Isolate ID & Location of collection & Cultivar from which isolate was recovered \\
\hline 09HOR05 & Horsham, Victoria & PBA Slasher \\
09KAN08 & Kaniva, Victoria & Howzat \\
09KAN19 & Kaniva, Victoria & Genesis 090 \\
09KIN06 & Kingsford, South Australia & Howzat \\
09KIN13 & Kingsford, South Australia & Genesis 509 \\
09MEL04 & Melton, South Australia & Almaz \\
\hline
\end{tabular}

Ten chickpea genotypes were selected as representative of a range of genotypes used in current cropping and breeding programs, together with two highly susceptible genotypes (Table 2). Chickpea plants were grown in 20 $\mathrm{cm}$ diameter pots containing commercial potting mix (BioGro, Australia), four plants per pot. Three replicates were sown for each of the genotype $\mathrm{x}$ isolate combinations for each of the seedling and maturity experiments. The cultivar Howzat was used as a susceptible control. Plants used for the seedling experiment were grown in a shade house facility, and plants used for the detached leaf assay at maturity were grown in a glasshouse, at the Grains Innovation Park, Department of Primary Industries, Horsham, Victoria.

Table 2. Chickpea genotypes and their assigned Ascochyta blight resistance ratings

\begin{tabular}{lll}
\hline Chickpea genotype & Resistance & Reference \\
\hline 90102-5Q-1103 & Resistant & K. Hobson (pers. comm.) \\
Genesis 090 & Resistant & Pulse Australia (2011) \\
ICC3996 & Resistant & Nasir et al., (2000) \\
PBA HatTrick & Resistant & Pulse Breeding Australia (2009) \\
94-121*99V4006 & Moderately resistant & K. Hobson (pers. comm.) \\
Flipper & Moderately resistant & Pulse Australia (2009b) \\
Genesis 114 & Moderately resistant & Pulse Australia (2009c) \\
Almaz & Moderately resistant - moderately susceptible & Pulse Australia (2009a) \\
Yorker & Moderately resistant - moderately susceptible & Pulse Australia (2009d) \\
Howzat & Moderately susceptible & Pulse Australia (2009e) \\
Kaniva & Susceptible & Carter (1999) \\
Lasseter & Susceptible & Carter (1999)
\end{tabular}




\section{2 Inoculation and Bioassay}

The seedling experiment was as described in Elliott et al. (2011), and involved inoculation of 2-week-old seedlings followed by scoring of leaf symptoms every 7 days for 4 weeks. For the maturity experiment, leaves were taken from plants when flowering had begun for all varieties (9-14 weeks after sowing). Leaves were detached using a sterile scalpel and surface sterilised by placing in a $2.6 \%$ sodium hypochlorite solution for two minutes, and then rinsed in sterile water. Leaves were subsequently placed on filter paper in a laminar flow and allowed to air dry. Once dry, they were transferred to $0.5 \%$ water agar plates, eight leaves per plate, three replicate plates of each isolate x cultivar combination. Previously, the disease responses of detached chickpea leaves to Ascochyta rabiei were correlated with those of field experiments. Dolar, Tenuta, and Higgins (1994) found this to be the case as long as recently fully expanded leaves were used, and not the oldest leaflets, which may be influenced by senescence effects.

Inoculum was produced as described in Elliott et al. (2011) without the use of Tween 20. A single $15 \mu \mathrm{L}$ drop of inoculum $\left(1 \times 10^{5}\right.$ spores $\left./ \mathrm{ml}\right)$ was placed onto the upper surface of each leaf and plates were incubated at $20 \pm 3^{\circ} \mathrm{C}$ under a continuous cycle of $14 \mathrm{~h}$ of light and $10 \mathrm{~h}$ of dark. Leaves were assessed under the microscope for percentage area of the leaf affected each day for seven days.

The area under the disease progress curve (AUDPC) was calculated for both seedling and maturity experiments using the following equation:

$$
\operatorname{AUDPC}=\Sigma\left[\left(\mathrm{X}_{\mathrm{i}}+\mathrm{X}_{\mathrm{i}+1}\right) / 2\right]\left(\mathrm{t}_{\mathrm{i}+1}-\mathrm{t}_{\mathrm{i}}\right)
$$

where, $\mathrm{X}_{\mathrm{i}}$ is the blight score (percentage leaf area affected) of the $i$ th evaluation, $\mathrm{X}_{\mathrm{i}+1}$ is the blight score of the $i+$ 1 th evaluation and $\left(t_{i+1}-t_{i}\right)$ is the number of days between the evaluations. Minitab ${ }^{\circledR}$ Statistical Software (release 15.1.1.0) was used for Analysis of Variance.

Simultaneously, a viability check was completed of each spore solution. For this, a $2 \mu \mathrm{L}$ drop of each solution was placed onto the surface of a V8 agar plate. Using a sterile glass rod, the drop was gently spread out, and the placement of the solution was marked on the underneath of the plate with a permanent marker. Plates were incubated under continuous light at $20 \pm 3^{\circ} \mathrm{C}$ for $48 \mathrm{~h}$ and examined under a microscope to assess spore viability. An inoculum solution would have been considered unviable if a constant spread of germinated spores was not observed.

\section{Results}

Significant differences $(\mathrm{P}<0.000)$ were observed in the mean isolate disease progressions among host genotypes at both seedling (Figure 1) and maturity (Figure 2) growth stages. Also the isolates had significantly different $(\mathrm{P}<0.000)$ disease progressions in mean reactions among the host genotypes (Figure 3$)$. The independent isolate $\mathrm{x}$ host disease progress interactions were significantly different at maturity $(\mathrm{P}<0.000)$ but not at seedling $(\mathrm{P}<0.072)$ stage.

Mean AUDPC values at the seedling stage generally ranked host genotypes in accordance with their publicised resistance rating (Table 2). Genesis 090 (resistant) possessed the lowest, and Lasseter and Kaniva (susceptible) possessed the highest AUDPC values. However, several of these expected phenotypic ratings were not retained at maturity; in particular the "resistant" landrace ICC3996 appeared significantly more susceptible, as did the derived breeding line $94-121 * 99 \mathrm{~V} 4006$. In contrast, the cultivar Yorker, known to be moderately resistant to moderately susceptible (Pulse Australia 2009e), ranked significantly more resistant at maturity than at seedling stage compared to other chickpea genotypes. Meanwhile, Genesis 090 was stably resistant at both assessed growth stages. 


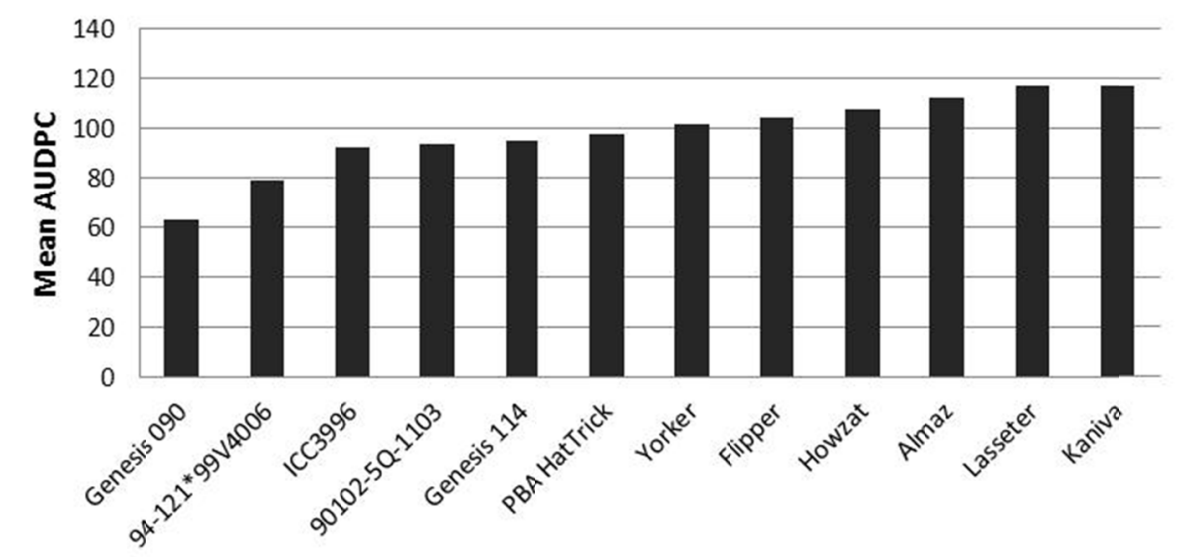

Chickpea genotype

Figure 1. Mean area under the disease progress curve for each host genotype at the seedling stage (LSD $=19.43)$

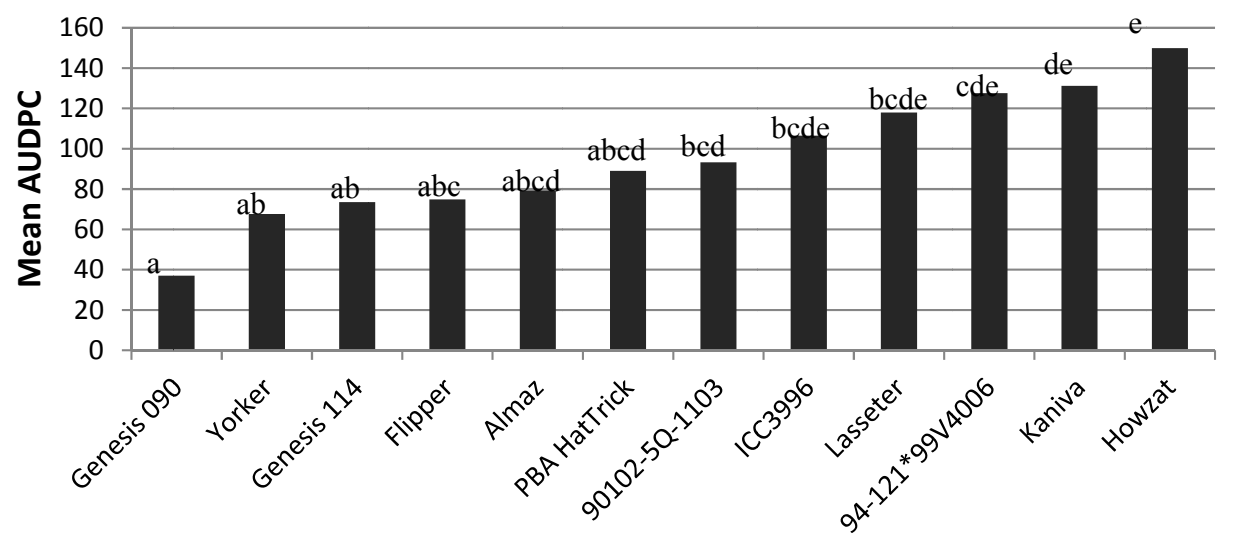

Chickpea genotype

Figure 2. Mean area under the disease progress curve for each host genotype at maturity (LSD $=52.86$ )

Among the six isolates assessed, 09MEL04 was the least aggressive, and 09KAN19 was the most aggressive at both host growth stages.

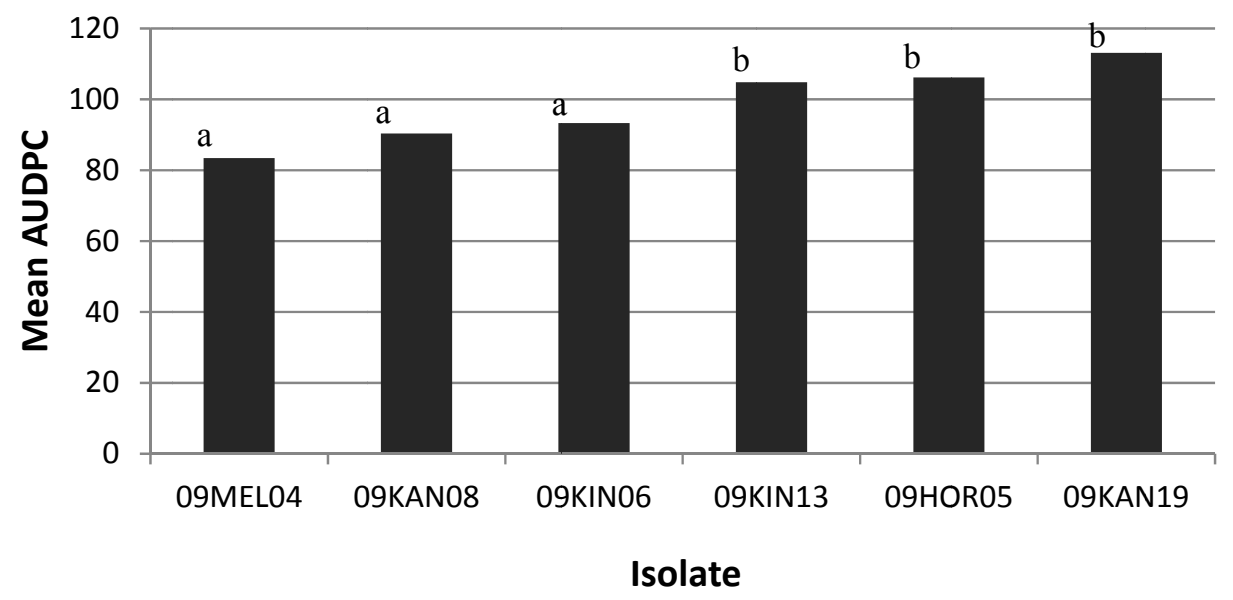

Figure 3. Mean area under the disease progress curve for each isolate at the seedling stage ( $\mathrm{LSD}=10.66)$ 


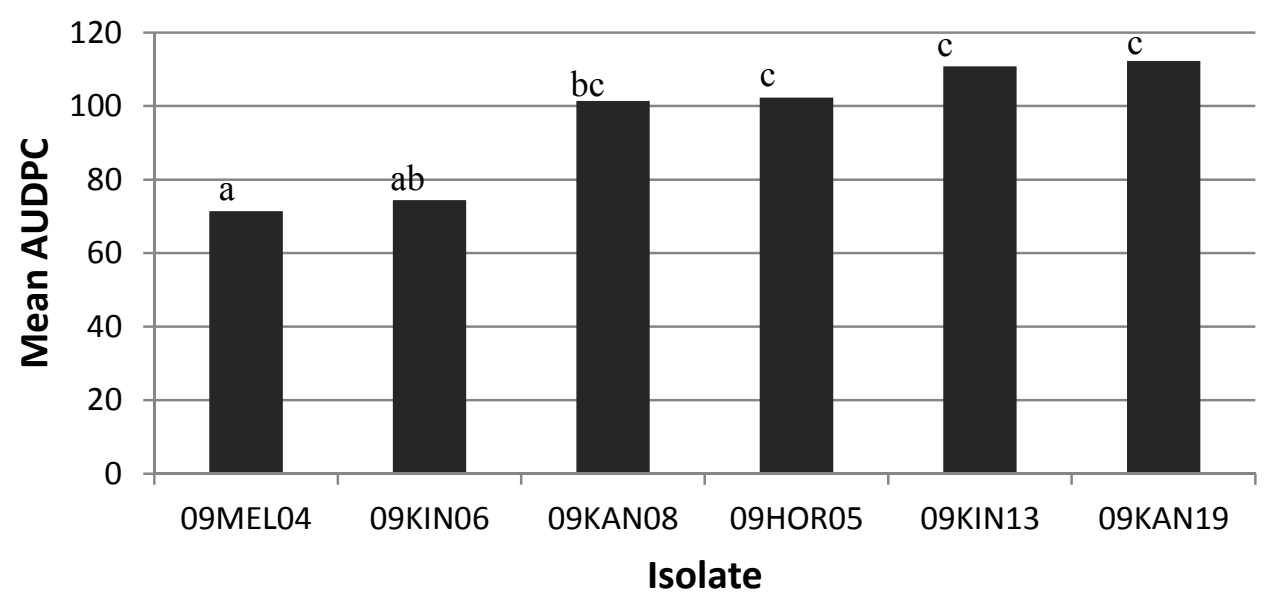

Figure 4. Mean area under the disease progress curve for each isolate at maturity $(\operatorname{LSD}=27.39)$

\section{Discussion}

Significant differences in disease reaction to A. rabiei due to plant age among parental and breeding lines were detected in the current study. For example, the line $94-121 * 99 \mathrm{~V} 4006$ was resistant at seedling stage, but had one of the highest mean AUDPC values at maturity. A similar reduction in resistance at plant maturity compared to the seedling stage had previously been demonstrated for genotypes classified as moderate or highly resistant in the USA and India (Chongo \& Gossen, 2001; Basandrai et al., 2007; Sharma et al., 2010). This highlights potential inefficiencies in resistance breeding based on selections made at a single growth stage (particularly at seedling stage only). This may subsequently result in genotypes that do not maintain resistance throughout the cropping season and an increased dependence on fungicides.

Meanwhile, the "moderately resistant to moderately susceptible" Yorker had the second lowest mean AUDPC value at maturity, indicating comparatively good resistance. Flipper and Genesis 114 also displayed greater resistance at maturity than other cultivars that are rated as more resistant. Since resistance is conditioned by multiple quantitative genetic effects (Gowen, Orton, Thurley, \& White, 1989; Vail \& Banniza, 2008; Flandez-Galves et al., 2003a) with a relatively large environmental influence (Trapero-Casas \& Kaiser, 1992), different genes and possibly pathways may be in operation at different growth stages. This has previously been shown for Ascochyta blight of pea (Prioul, Frankewitz, Deniot, Morin, \& Baranger, 2004). Selection and integration of the major genetic components of both seedling and maturity resistance would likely increase the durability of resistance and lead to potential for less fungicide applications.

Of the genotypes assessed, Genesis 090 contained the highest level of resistance at both growth stages. This supports the claim that Genesis 090 is the benchmark Ascochyta resistant chickpea for southern Australia (Pulse Australia 2011). Nevertheless, application of a fungicide at podding remains a part of the prescribed disease management program for this genotype since highly aggressive isolates are present in the Australian isolate population with potential to reduce quality and yield (Elliott et al., 2011).

Finally, the significant differences detected in disease severity due to isolate choice again demonstrate that isolate selection will be critical when screening future breeding material (Elliott et al., 2011). In particular, two isolates in the current study (09KAN08 and 09KIN13) caused significantly high levels of disease on Genesis 090. Hence, they should be included in future controlled environment screening and their prevalence should be monitored for using screening and possible DNA marker techniques (Leo et al., 2011) in the Genesis 090 growing locations as a pre-emptive warning for possible breakdown.

\section{Acknowledgements}

The authors acknowledge the Australian chickpea breeders and pathologists for their advice on host genotypes, Audrey Leo and Jenny Davidson for assistance with the collection of isolates in Victoria and South Australia.

\section{References}

Basandrai, A. K., Basandrai, D., Pande, S., Sharma, M., Thakur, S. K, \& Thakur, H. L. (2007). Development of Ascochyta blight (Ascochyta rabiei) in chickpea as affected by host resistance and plant age. European Journal of Plant Pathology, 11, 77-86. http://dx.doi.org/10.1007/s10658-007-9123-y 
Carter, J. M. (1999). Chickpea Growers guide: a guide for the production of chickpeas. Agriculture Victoria, Department of Natural Resources and Environment.

Chongo, G, \& Gossen, B. D. (2001). Effect of plant age on resistance to Ascochyta rabiei in chickpea. Canadian Journal of Plant Pathology, 23, 358-363. http://dx.doi.org/10.1080/07060660109506956

Dolar, F. S., Tenuta, A, \& Higgins, V. J. (1994). Detached leaf assay for screening chickpea for resistance to Ascochyta blight. Canadian Journal of Plant Pathology, 16(3), 215-220. http://dx.doi.org/10.1080/07060669409500756

Elliott, V., Taylor, P. W. J, \& Ford, R. (2011). Pathogenic variation within the 2009 Australian Ascochyta rabiei population and implications for future disease management strategy. Australasian Plant Pathology, 40, 568-574. http://dx.doi.org/10.1007/s13313-011-0087-1

Flandez-Galvez, H., Ford, R., Ades, P. K., Pang, E. C. K, \& Taylor, P. W. J. (2003a). QTL analysis for Ascochyta blight resistance in an intraspecific population of chickpea (Cicer arietinum L.). Theoretical and Applied Genetics, 107, 1257-1265. http://dx.doi.org/10.1007/s00122-003-1371-4

Flandez-Galvez., H., Ford, R., Pang, E. C. K, \& Taylor., P. W. J. (2003b). An intraspecific linkage map of the chickpea (Cicer arietinum L.) genome based on sequence tagged microsatellite site and resistance gene analog markers. Theoretical and Applied Genetics, 106, 1447-1456.

Gowen., S. R., Orton, M., Thurley, B., \& White, A. (1989). Variation in pathogenicity of Ascochyta rabiei on chickpeas. Tropical Pest Management, 35, 180-186. http://dx.doi.org/10.1080/09670878909371353

Kaiser, W. J., \& Muehlbaur, F. J. (1988). An outbreak of Ascochyta blight of chickpea in the Pacific Northwest, USA, in 1987. International Chickpea Newsletter, 18, 16-17.

Leo, A. E., Ford, R., Linde, C. C., Shah, R. M., Oliver, R., Taylor, P. W. J., \& Lichtenzveig, J. (2011). Characterization of fifteen newly developed microsatellite loci for the chickpea fungal pathogen Ascochyta rabiei. Molecular Ecology Resources, 11, 418-421. PMid:21429157

Lichtenzveig, J., Shtienberg, D., Zhang, H. B., Bonfil, D. J., \& Abbo, S. (2002). Biometric analyses of the inheritance of resistance to Didymella rabiei in chickpea. Phytopathology, 92, 417-423. http://dx.doi.org/10.1094/PHYTO.2002.92.4.417

Nasir, M., Bretag, T. W., Kaiser, W. J., Meredith, K. A., \& Brouwer, J. B. (2000). Screening chickpea germplasm for ascochyta blight resistance. Australasian Plant Pathology, 29, 102-107. http://dx.doi.org/10.1071/AP00018

Navas-Cortés, J. A., Pérez-Artés, E., Jiménez-Diaz, R. M., Llobell, A., Bainbridge, B. W., \& Heale, J. B. (1998). Mating type, pathotype, and RAPDs analysis in Didymella rabiei, the agent of Ascochyta blight of chickpea. Phytoparasitica, 26, 199-212. http://dx.doi.org/10.1007/BF02981435

Nene, Y. L, \& Reddy, M. V. (1987). Chickpea diseases and their control. In M. C. Saxena, \& K. B. Singh (Eds.), The chickpea (pp. 233-270). Oxon: CAB International.

Pande, S., Siddique, K. H. M., Kishore, G. K., Bayaa, B., Gaur, P. M., Gowda, C. L. L., Bretag, T. W., \& Crouch, J. H. (2005). Ascochyta blight of chickpea (Cicer arietinum L.): a review of biology, pathogenicity, and disease management. Australian Journal of Agricultural Research, 56, 317-332. http://dx.doi.org/10.1071/AR04143

Prioul, S., Frankewitz, A., Deniot, G., Morin, G, \& Baranger, A. (2004). Mapping of quantitative trait loci for partial resistance to Mycosphaerella pinodes in pea (Pisum sativum L.), at the seedling and adult plant stages. Theoretical and Applied Genetics, 108, 1322-1334. http://dx.doi.org/10.1007/s00122-003-1543-2

Pulse Australia. (2008). Genesis 425. Pulse variety management package. Retrieved from http://www.pulseaus.com.au/pdf/Genesis\%20425\%20VMP.pdf

Pulse Australia. (2009a). Almaz. Pulse variety management package. Retrieved from http://www.pulseaus.com.au/pdf/Almaz\%20VMP.pdf

Pulse Australia. (2009b). Flipper. Pulse variety management package. Retrieved from http://www.pulseaus.com.au/pdf/Flipper\%20VMP.pdf

Pulse Australia. (2009c). Genesis 114. Pulse variety management package. Retrieved from http://www.pulseaus.com.au/pdf/GENESIS\%20114\%20VMP.pdf 
Pulse Australia. (2009d). Genesis 509. Pulse variety management package. Retrieved from http://www.pulseaus.com.au/pdf/GENESIS\%20509\%20VMP.pdf

Pulse Australia. (2009e). Yorker. Pulse variety management package. Retrieved from http://www.pulseaus.com.au/pdf/Yorker\%20VMP.pdf

Pulse Australia. (2011). Genesis 090. Pulse variety management package. Retrieved from http://www.pulseaus.com.au/pdf/GENESIS\%20090\%20VMP.pdf

Pulse Australia. Chickpeas in South Australia \& Victoria. Retrieved from http://www.pulseaus.com.au/pdf/Chickpeas\%20for\%20SA\%20\&\%20Vic.pdf

Pulse Breeding Australia. (2009). PBA HatTrick. Variety management package. Retrieved from http://www.pulseaus.com.au/pdf/Genesis\%20425\%20VMP.pdf

Santra, D. K., Tekeoglu, M., Ratnaparkhe, M., Kaiser, W. J., \& Muehlbaur, F. J. (2000). Identification and Mapping of QTLs Conferring Resistance to Ascochyta Blight in Chickpea. Crop Science, 40, 1606-1612. http://dx.doi.org/10.2135/cropsci2000.4061606x

Sharma, M., Pande, S., \& Rathore, A. (2010). Effect of growth stages of chickpea on the genetic resistance of Ascochyta blight. European Journal of Plant Pathology, 128, 325-331. http://dx.doi.org/10.1007/s10658-010-9641-x

Trapero-Casas, A., \& Kaiser, W. J. (1992). Influence of temperature, wetness period, plant age and inoculum concentration on infection and development of Ascochyta blight. Phytopathology, 82, 589-596. http://dx.doi.org/10.1094/Phyto-82-589

Udupa, S. M., \& Baum, M. (2003). Genetic dissection of pathotype-specific resistance to Ascochyta blight disease in chickpea (Cicer arietinum L.) using microsatellite markers. Theoretical and Applied Genetics, 106, 1196-1202. PMid: 12748770

Vail, S., \& Banniza, S. (2008). Structure and pathogenic variability in Ascochyta rabiei populations on chickpea in the Canadian prairies. Plant Pathology, 57, 665-673. http://dx.doi.org/10.1111/j.1365-3059.2008.01837.x

\section{Copyrights}

Copyright for this article is retained by the author(s), with first publication rights granted to the journal.

This is an open-access article distributed under the terms and conditions of the Creative Commons Attribution license (http://creativecommons.org/licenses/by/3.0/). 